\title{
Assess the Effectiveness of Health Litracy and Behavioural Changes on Household Gas Cylinder Usage and Safety Measures among Womens Living in Selected Area
}

\author{
Dr. Bhuvaneswari $\mathrm{G}^{1^{*}}$, Benitta Thanaseeli $\mathrm{S}^{2}$, Kalichwaran $\mathrm{S}^{2}$, Divya $\mathrm{M}^{2}$, Hemalatha $\mathrm{M}^{2}$ \\ ${ }^{1}$ Associate Professor, Department of Community Health Nursing, Saveetha College of Nursing, SIMATS, Chennai, India \\ ${ }^{2}$ B.Sc (N) IV Year, Saveetha College of Nursing, SIMATS, Chennai, India
}

\author{
DOI: $10.36348 /$ sjnhc.2020.v03i02.005 \\ | Received: 06.02.2020 | Accepted: 16.02.2020 | Published: 19.02.2020 \\ *Corresponding author: Dr. Bhuvaneshwari G

\section{Abstract}

Introduction: Liquified petroleum gas can be used as a power source for combined heat and power technologies (CHP). CHP is the process of generating both electrical power and useful heat from a single fuel source. This study assess the effectiveness of health litracy and behavioral changes on the household gas cylinder usage and safety measures among women's. Methodology: Descriptive design non experimental research approach was used to sample 100 respondents from rural areas Thiruvallur district. A structure interview schedule was used to collect data from the respondents. These were analyzed by using (frequency, percentage, mean and standard deviation and inferential (chi square) statistics. Results: In frequency overall knowledge aspects on household gas cylinder usage and safety measures, the pre test mean value is 7.85 with standard deviation of 2.1047 and post test score Mean is 11.34 and SD is 4.3256. Discussion: Based on the findings of the study to improved the Liquified petroleum gas gas cylinder usage and safety measures living of the people in the rural areas.

Keywords: Liquified petroleum gas, CHP, Gas Cylinder.

Copyright @ 2020: This is an open-access article distributed under the terms of the Creative Commons Attribution license which permits unrestricted use, distribution, and reproduction in any medium for non-commercial use (NonCommercial, or CC-BY-NC) provided the original author and source are credited.

\section{INTRODUCTION}

A gas cylinder or tank is a pressure vessel for storage and containment of gases at above atmospheric pressure. High-pressure gas cylinders are also called bottles. Inside the cylinder the stored contents may be in a state of compressed gas, vapor over liquid, supercritical fluid, or dissolved in a substrate material, depending on the physical characteristics of the contents. A typical gas cylinder design is elongated, standing upright on a flattened bottom end, with the valve and fitting at the top for connecting to the receiving apparatus Liquified petroleum gas can be used as a power source for combined heat and power technologies (CHP). CHP is the process of generating both electrical power and useful heat from a single fuel source. This technology has allowed Liquified petroleum gas to be used not just as fuel for heating and cooking, but also for decentralized generation of electricity.

Production and consumption of almost any type of energy have environmental impacts. Harvesting of fuel wood, in particular, contributes to deforestation, soil erosion, and desertification. In Nigeria, harvesting of fuel wood contributes to deforestation at a rate of about 400,000 hectares per year [1].

If this trend continues the country's forest resources could be completely depleted by 2020 . Use of fuel wood as an energy source can also contribute to the accumulation of $\mathrm{CO} 2$, the main greenhouse gas, both because burning fuel wood produces $\mathrm{CO} 2$, and because deforestation destroys an important $\mathrm{CO} 2$ sink [2].

In addition, use of biomass fuel for cooking is a major cause of health problems in developing countries due to indoor air pollution [12, 13]. For example, the world health organization (WHO) estimates that 1.5 million premature death per year are directly attributed to indoor air pollution from the use of solids fuels [5]. Use of biomass in traditional stoves expose the users, mainly woman and children, to high levels of indoor air pollution [14].

Household fuel choice also depends on other factors, which makes knowledge of the determinants of urban households' choice of fuel important. In the literature on household energy demand and choice, it 
has been argued that households with low levels of income rely on biomass fuels, such as wood and dung, while those with higher incomes consume energy that is cleaner and more expensive, such as electricity. Those households in transition-between traditional and cleaner (and more efficient) energy sources - consume what are called transition fuels, such as kerosene and charcoal. While this is a simpler version of the "energy ladder hypothesis," it is also presented in the literature with more elaborate intermediate steps [3].

World Health Organization also established that close to 4 million people die prematurely from illness attributable to household air pollution from inefficient cooking practices using polluting stoves paired with solid fuels and kerosene [4].

The use of biomass is not in itself a cause for concern. However, when resources are harvested unsustainably and energy conversion technologies are inefficient, there are serious adverse consequences for health, the environment and economic development. It further stated that about 1.3 million people -mostly women and children die prematurely every year because of exposure to indoor air pollution from biomass. Valuable time and effort is devoted to fuel collection instead of education or income generation, environmental damage can also result, such as land degradation and regional air pollution [5].

The global burden of disease from Household air pollution is concentrated in the poorest household in low income countries. However given evidence of relationship between household air pollution and low birth weight and preterm weight this two health outcome are not included in related global burden of disease estimate [6].

The educating women about health risks from smoke exposure will do little changes their daily need for cooking under high exposure conditions. In these settings, women are constrained by fuel supply and cost, the need to prepare food in a certain way, or other household members who prefer to use the traditional stove instead of the gas stove [7].

\section{OBJECTIVES}

- To determine the effectiveness of health literacy and behavioral changes on household gas cylinder usage and safety measures among womens.
- To assess the level of effectiveness of health literacy and behavioral changes on household gas cylinder usage and safety measures among Women's.

- To associate the level of effectiveness of health literacy and behavioral changes on household and safety measures among women's and their selected demographic variables.

\section{METHODOLOGY}

An pre experimental reaearch approach was chosen to assess the effectiveness of health literacy and behavioral changes on household gas cylinder usage and safety measures among women's. The study was conducted at Nemam, Kizhachery and Mappedu by using purposive sampling technique. The data were collected from the 100 samples of women's. The samples who meet the inclusion criteria were selected for the study. The data collection was collected by using questionnaires on the demographic variable such as age, education status, number of family members, socio economic status, family income, marital status, occupation. Self structured questionnaire to assess the knowledge on household gas cylinder usage and safety measures among women's,

\section{RESULT}

Out of 100 samples $35 \%$ belongs to age group 20-30 years old, $34 \%$ belong to educational status primary school, $30 \%$ belongs to number of 4 family members, $52 \%$ were middle class, $33 \%$ were 10000 15000 , $67 \%$ were married and $53 \%$ were woking in private occupation.

Mean and standard deviation on selected household gas cylinder usage and safety measures (Table-1, Figure-1). In frequency overall knowledge aspects on household gas cylinder usage and safety measures, the pre test mean value is 7.85 with standard deviation of 2.1047 and post test score Mean is 11.34 and SD is 4.3256 (Table-2).

Pre test was $91 \%$ of inadequate effectiveness of health literacy and behavioral changes among women's, $9 \%$ of moderate effectiveness of health literacy and behavioral changes among women's and post test score was $8 \%$ of inadequate effectiveness of health literacy and behavioral changes among womens, $58 \%$ of moderate knowledge among women's and $36 \%$ of adequate knowledge (Table-3).

Table-1: Comparison of the pre test and post test of effectiveness of health literacy and behavioral changes on household gas cylinder usage and safety measures among women's

\begin{tabular}{|l|l|l|}
\hline level of effectiveness of health literacy and behavioral changes among women's & Mean & SD \\
\hline Pre test & 7.85 & 2.1047 \\
\hline Post test & 11.34 & 4.3256 \\
\hline
\end{tabular}


Table-2: Assessment of level of effectiveness of health literacy and behavioral changes among momen's

\begin{tabular}{|l|l|l|l|}
\hline $\begin{array}{l}\text { level of effectiveness of health literacy and } \\
\text { behavioral changes among women's }\end{array}$ & $\begin{array}{l}\text { Pre test frequency } \\
(\mathbf{N = 1 0 0 )}\end{array}$ & $\begin{array}{l}\text { Post test frequency } \\
(\mathbf{N}=\mathbf{1 0 0})\end{array}$ & \multirow{2}{*}{14.34} \\
\cline { 1 - 3 } Inadequate knowledge & 91 & 08 & \\
\hline Moderate & 09 & 58 & 36 \\
\hline Adequate & 0 & & \\
\hline
\end{tabular}

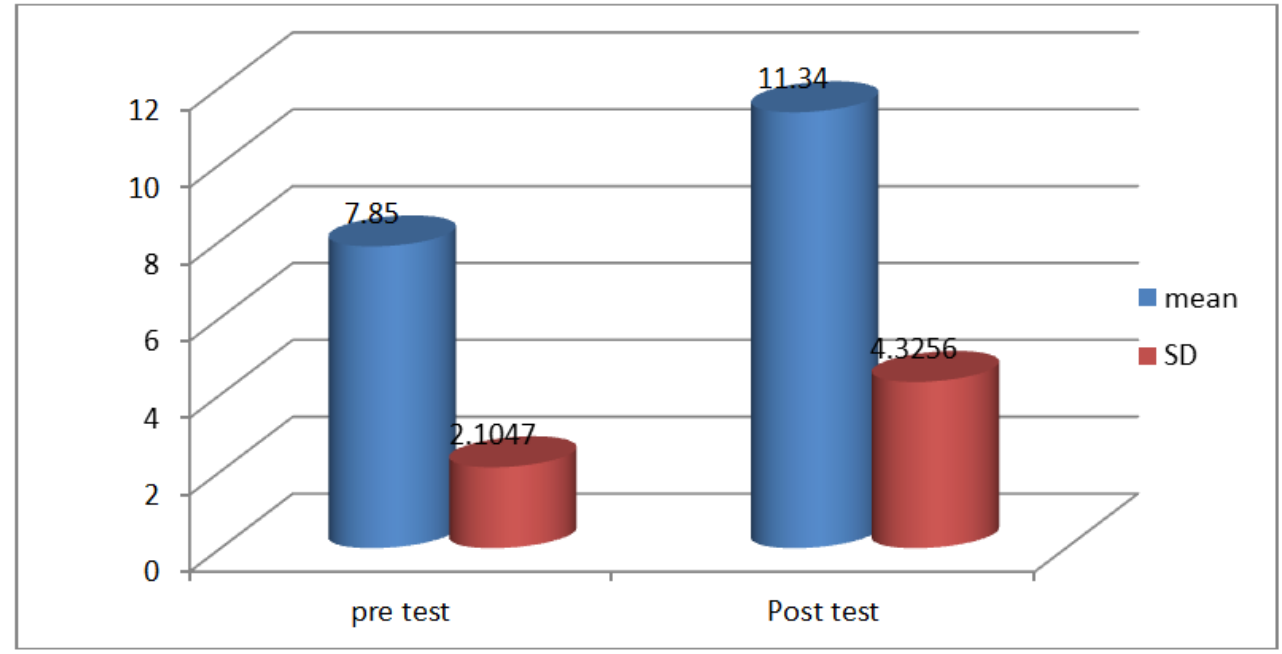

Fig-1: Comparison of the pre test and post test of effectiveness of health literacy and behavioral changes on household gas cylinder usage and safety measures among women's

\section{DISCUSSION}

The main focus of the study to assess the effectiveness of health literacy and behavioral changes on household gas cylinder usage and safety measures among women's. total 100 samples we are selected. The present study was under taken to assess the effectiveness of health literacy and behavioral changes on household gas cylinder usage and safety measures among women's living in selected areas. A descriptive design was adopted with pre test and post test for the study. The level of knowledge was assessed by structured questionnaire. The result and discussion of the study are based on the findings obtained from the statistical analysis.

The main study findings and it is supportive study to be include a study to S. M. Tauseef, et al., conducted risk of domino effect associated with the storage of Liquified petroleum gas and safety codes for accident prevention. Due to the very extensive and continuous use of Liquified petroleum gas the risk of Liquified petroleum gas related accident is ever present. This paper deals with the risk associated with the storage of Liquified petroleum gas in large installations and reviews the safety codes prescribed by different agencies a crose the world to minimize the risk. The comparable views of the stipulations of different codes for different characteristics [8].

Supportive study to be include a study to Maxwell dalaba et al., conducted a crass sectional study, liquefied petroleum gas supply and demand for cook in northern Ghana. They interviewed 16 Liquified petroleum gas suppliers (stove, cylinder and fuel) as well as 592 households in the nankana districts, data were analyzed using STATA. A linear probability model regression was conducted to assess factors associated with Liquified petroleum gas ownership among urban households [9].

Supportive study to be include a study to Daniel pope et al., (October 2018) conducted a cross sectional study, household determents of liquefied petroleum gas as a cooking fuel in SW Cameroon that the currently $70 \%$ of the population in Cameroon are the reliant an solid fuel for cooking and the associated household air population contributes to significant mortality and morbidity in the country, survey of 1577 households using socio demographic questions. Results from their census lower levels of poverty and high levels of education than Cameroon, find Liquified petroleum gas usage well below target levels set by the Cameroon government [10].

Supportive study to be include a study to Lisa M. Thompson et al., (February 2018) conducted a designing a behavioral intervention using the COM-B model and the theoretical domains frame work to promote gas stove using rural. A formative research study used for phase 1 is 25 pregnant women and phase 2 is 25 pregnant women's. The findings of the study reveals wood stove use dropped upon introduction of the gas stove from 6.4 hours to 1.9 hours. This model developed a behavioral intervention that promotes household level sustained use of Liquified petroleum gas stoves [11]. 


\section{ACKOWLEDGEMENT}

The author are thankful to Prof. Dr. S. Kalabarathi, principal of Saveetha college of nursing, SIMATS. The authors also wish cordial thanks to Mrs. L. Parimala, M.Sc (N) Vice Principal of Saveetha college of nursing, SIMATS, for their encouragement, valuable suggestions, support and advice given throughout the study.

Conflict of Interest: The author declare no conflict of interest.

\section{REFERENCE}

1. Oladosu, G. A., \& Adegbulugbe, A. O. (1994). Nigeria's household energy sector: Issues and Supply/Demand Frontiers. Energy Policy, 22(6): 538-549.

2. Mekonnen, A., \& Köhlin, G. (2009). Determinants of household fuel choice in major cities in Ethiopia. Enviroment for Development Discussion Paper Series, EfD DP 08-18:19.

3. Hosier, R. H., \& Dowd, J. (1987). Household Fuel Choice in Zimbabwe: An Empirical Test of the Energy Ladder Hypothesis. Resources and Energy, 9:347-361.

4. World Health Organisation. (2018): Household air pollution and health. Retrieved on $27^{\text {th }}$ June, 2018 Available on http://w w w.who.int/news-room/fact- sheets/detail/household - air- pollution - and -health

5. International Energy Agency (IEA). (2006). World energy outlook: energy for cooking in developingcountries.Availableonhttps://www.iea.o $\mathrm{rg} /$ publications/freepublications/publication/ cooking .pdf

6. GBD. (2016). 2016 risk factors collaborators, global, regional and national comparative risk assessment of 84 behavioral, environmental and occupational. A systematic analysis of the global burden of the disease study.

7. Challenges and opportunities of a women entrepreneur model: LPG use in Guatemala.

8. Tauseef, S. M., Abbasi, T., Thiruselvi, D., \& Abbasi, S. A. (2017). The risk of domino effect associated with the storage of liquefied petroleum gas (LPG) and the safety codes for accident prevention. International Journal of Engineering, Science and Mathematics, 6(7), 456-482.

9. Dalaba, M., Alirigia, R., Mesenbring, E., Coffey, E., Brown, Z., Hannigan, M., ... \& Dickinson, K. L. (2018). Liquified Petroleum Gas (LPG) Supply and Demand for Cooking in Northern Ghana. EcoHealth, 15(4), 716-728.

10. Daniel, P. (2018). Household deternantsof liquefied petroleum gas as a cooking fuel.

11. Thompson, L. M., Diaz-Artiga, A., Weinstein, J. R., \& Handley, M. A. (2018). Designing a behavioral intervention using the COM-B model and the theoretical domains framework to promote gas stove use in rural Guatemala: a formative research study. BMC public health, 18(1), 253.

12. Bruse, M. (2000, August). Assessing thermal comfort in urban environments using an integrated dynamic microscale biometeorological model system. In Third Symposium on the Urban Environment (pp. 159-160).

13. Ezzati, M., \& Kammen, D. M. (2001). Quantifying the effects of exposure to indoor air pollution from biomass combustion on acute respiratory infections in developing countries. Environmental health perspectives, 109(5), 481-488.

14. Dzioubinski, O., \& Chipman, R. (1999). Trends in consumption and production: household energy consumption (No. 6). United Nations, Department of Economic and Social Affairs. 